\title{
APROVEITAMENTO DO SORO DE LEITE PROVENIENTE DA PRODUÇÃO DO QUEIJO DO SERRO PARA FABRICAÇÃO DE DOCE DE LEITE: VIABILIDADE ECONÔMICA
}

\section{Usage of the milk whey originated from Serro cheese to manufacture Dulce de Leche: economic viability}

\author{
Fabiana Regina Lima ${ }^{1 *}$, Larissa de Oliveira Ferreira Rocha ${ }^{1}$
}

\begin{abstract}
RESUMO
O estado de Minas Gerais é reconhecidamente o mais tradicional produtor de queijos do Brasil e uma importante característica desta produção é o modo artesanal de fabricação. Cerca de $90 \%$ do volume do leite utilizado na fabricação de queijo resulta em soro. O aproveitamento adequado do soro de leite é de grande importância em função de sua qualidade nutricional, do seu volume e de seu poder poluente. $\mathrm{O}$ objetivo deste trabalho foi estudar a viabilidade econômica de produção de doce de leite com adição de soro de leite proveniente da fabricação do queijo do Serro. Foram elaboradas formulações de doce de leite com concentrações de 10\%, 20\%, $30 \%, 40 \%$ e $50 \%$ soro. O investimento total para a produção do doce foi de R\$ 359,26 (US\$ 110.72). O custo fixo ficou em R $\$ 18,00$ (US\$ 5.55). Os custos variáveis ficaram entre R\$81,07 (US\$24.98) e R\$ 96,91 (US\$ 29.87). O preço de venda variou entre R $\$ 5,36$ (US\$1.65) e R $\$ 5,47$ (US\$1.69). Em relação aos indicadores de desempenho, a formulação com maior porcentagem de soro se mostrou mais lucrativa. A rentabilidade foi de aproximadamente $27 \%$ para a formulação com menor porcentagem de soro. O prazo de retorno do investimento foi de 4 meses para todas as formulações. O ponto de equilíbrio para a produção do doce se encontra na venda de 8 unidades. Diante dos resultados, verificou-se que é viável economicamente o aproveitamento do soro para a produção de doce de leite.
\end{abstract}

Palavras-chave: soro lácteo; aproveitamento; lácteo concentrado; viabilidade econômica.

1 Universidade Federal dos Vales do Jequitinhonha e Mucuri (UFVJM), Rodovia MGT 367, Km 583, 5000, Alto da Jacuba, 39100-000, Diamantina, MG, Brasil. E-mail: fabianalima1818@hotmail.com.

* Autor para correspondência. 


\begin{abstract}
The State of Minas Gerais is known for being the most traditional cheese producer in Brazil and part of those products are artisanal. About $90 \%$ of the milk used to produce cheese results in whey. Whey processing is of great importance due to its nutritional quality, volume and pollutant capacity. The aim of this study was to evaluate the economic viability of dulce de leche production with the addition of whey from Serro cheese production. Formulations of dulce de leche were elaborated added with whey concentrations of $10 \%, 20 \%, 30 \%, 40 \%$ and $50 \%$. The total investment for the production of the dulce de leche was R $\$ 359,26$ (US\$110.72). The fixed cost was R $\$ 18,00$ (US\$5.55). The variable costs stayed between R \$81,07 (US\$24.98) and $\mathrm{R} \$ 96,91$ (US\$29.87). The sales price varied between R \$5,36 (US\$1.65) and R \$5,47 (US\$1.69). The performance indicators showed that the formulation with the highest percentage of whey added was more profitable. The profitability was approximately $27 \%$ for the formulation with the lowest percentage of whey added. The return time for the investment was 4 months for all the formulations. The equilibrium point for dulce de leche production is at the sales of 8 units. It can be concluded that it is economically viable to utilize whey for the production of the dulce de leche.
\end{abstract}

Keywords: whey; utilization; concentrated lactoserum; economic viability.

\section{INTRODUÇÃO}

Minas Gerais é reconhecidamente o estado mais tradicional na produção de queijos no Brasil. Uma importante característica da produção de queijo em Minas Gerais é a sua fabricação artesanal, que representa uma parcela significativa de todo queijo do Estado, sendo as regiões de Araxá, Campos das Vertentes, Canastra, Cerrado, Serra do Salitre, Serro e Triângulo Mineiro consideradas tradicionais (OGAL, 2013; IMA, 2015).

O queijo Minas artesanal do Serro é fabricado a partir do leite cru adicionado do soro fermento e do coalho, coagulado à sua temperatura natural. Após a coagulação, a coalhada é deixada em repouso, seguido de agitação lenta, até a obtenção da massa firme. A partir daí, é eliminado parte do soro e feita à compressão da massa nas fôrmas com as mãos. A salga é realizada primeiro de um lado do queijo e, após algumas horas, do outro lado. O soro fermento, tradicionalmente conhecido como "pingo", é coletado de um dia para o outro em recipiente higienizado para ser usado na próxima fabricação (SANTOS, 2010). O soro fermento resultante da dessoragem de queijos salgados e colhido durante a noite, age como inibidor de algumas fermentações indesejáveis e confere ao queijo características típicas de sua variedade (MARTINS, 2006; SANTOS, 2010).

A região do Serro produz cerca de 3.100 toneladas de queijos por ano, constituindo o principal produto da região. É composto por 881 produtores, gerando 2.290 empregos diretos. Por mês, cerca de 25 toneladas são compradas pela Cooperativa dos Produtores Rurais do Serro, onde são classificados, embalados, identificados com o número do produtor e distribuídos para o varejo (EMATER, 2015).

No processo de fabricação de queijo não há conversão de cem por cento da matériaprima leite no produto queijo. Cerca de $90 \%$ do volume de leite utilizado na fabricação de queijos resulta em soro - 10 litros de leite produzem, aproximadamente, $1 \mathrm{~kg}$ de queijo e 9 litros de soro (ABREU, 2000). O soro de 
leite é um subproduto obtido por meio da fabricação de queijo ou da caseína. Apresenta-se na forma líquida e de cor amareloesverdeada (CARVALHO et al., 2013). O soro contém mais da metade dos sólidos presentes no leite, incluindo as proteínas do soro ( $20 \%$ da proteína total) e a maior parte da lactose, minerais e vitaminas hidrossolúveis (BALDASSO et al., 2011). As proteínas do soro lácteo apresentam excelente composição em aminoácidos, alta digestibilidade e biodisponibilidade de aminoácidos essenciais, portanto elevado valor nutritivo. Além das propriedades nutricionais, as proteínas de soro de leite têm propriedades funcionais que conferem propriedades físicas benéficas quando usadas como ingredientes em alimentos, principalmente devido a sua alta solubilidade, absorção de água, gelatinização e capacidades emulsificantes (SGARBIERI, 1996).

A identificação de alternativas para um adequado aproveitamento do soro de leite é de fundamental importância em função de sua qualidade nutricional, do seu volume e de seu poder poluente. Dentre as alternativas podem ser citadas o uso do soro in natura para alimentação animal, fabricação de ricota, fabricação de bebida láctea, concentração, produção de soro em pó, separação das proteínas e lactose, com posterior secagem. Essas por sua vez, constituem formas de valorização deste derivado lácteo, ao mesmo tempo contribuindo para a melhoria do meio ambiente e proporcionando ganhos às indústrias, porém, cada alternativa para ser aplicada, envolve análise técnica e econômica para sua viabilização (GIROTO; PAWLOWSKY, 2001).

No Brasil as indústrias de doce de leite têm substituído parcialmente o leite por soro na fabricação. Apesar da adição de soro não ser proibida, já que a legislação brasileira o classifica como ingrediente lácteo e o seu uso deve ser declarado, para não caracterizar uma fraude econômica (MACHADO, 2005).
Apesar das várias possibilidades de utilização do soro de leite, na maioria dos casos, o soro obtido na fabricação do queijo Minas artesanal do Serro é utilizado na alimentação animal. Sabendo que a concentração de uma mistura de leite, soro de leite e açúcar possibilita a obtenção de um doce de leite semelhante ao tradicional (PERRONE, 2006), o presente trabalho tem como objetivo estudar a viabilidade econômica de produção de doce de leite com adição de soro de leite proveniente da fabricação do queijo Minas artesanal da região do Serro, visando agregar valor a esse co-produto e aumentar a rentabilidade do produtor rural.

\section{MATERIAL E MÉTODOS}

\section{Formulação de doce de leite com adição de soro lácteo}

Para a fabricação do doce de leite com adição de soro lácteo utilizou-se leite integral pasteurizado, soro líquido proveniente da fabricação de queijos do Serro, açúcar cristal, bicarbonato de sódio e amido de milho. Foram utilizados potes de vidro com capacidade para 200 gramas com tampa rosqueável para envasar os doces.

Considerou-se, uma produção diária correspondente ao processamento de $20 \mathrm{~L}$ de matéria-prima (leite + soro). Foram elaboradas cinco formulações, com concentrações de soro de $10 \%, 20 \%, 30 \%, 40 \%$ e $50 \%$ de substituição de leite por soro. Os doces de leite foram produzidos conforme tecnologia sugerida por Martins; Lopes (1981). As formulações utilizadas encontram-se na Tabela 1.

As porcentagens de açúcar e amido foram calculadas em relação à mistura (leite + soro). Utilizou-se bicarbonato de sódio para neutralizar a acidez da mistura. 
Tabela 1 - Formulação utilizada na produção do doce de leite com adição de soro lácteo para avaliação da viabilidade econômica $(\mathrm{n}=3)$

\begin{tabular}{c|c|c|c|c}
\hline Formulações & $\begin{array}{c}\text { Leite } \\
(\%)\end{array}$ & $\begin{array}{c}\text { Soro } \\
(\%)\end{array}$ & $\begin{array}{c}\text { Açúcar } \\
(\%)\end{array}$ & $\begin{array}{c}\text { Amido } \\
(\%)\end{array}$ \\
\hline 1 & 90 & 10 & 20 & 0,5 \\
2 & 80 & 20 & 20 & 0,5 \\
3 & 70 & 30 & 20 & 0,5 \\
4 & 60 & 40 & 20 & 0,5 \\
5 & 50 & 50 & 20 & 0,5 \\
\hline
\end{tabular}

\section{Fabricação das formulações de doce de leite com adição de soro lácteo}

A produção do doce de leite foi realizada no Laboratório de Tecnologia de Alimentos do Curso de Engenharia de Alimentos da Universidade Federal dos Vales do Jequitinhonha e Mucuri - Campus Diamantina (MG). Foram utilizados fogão e panela industrial com capacidade de 20 litros, a mistura foi feita manualmente com a utilização de uma colher. Inicialmente, foram colocados na panela o leite e o soro, na devida proporção. Logo após, adicionou-se bicarbonato para a correção da acidez para $1 \mathrm{~g}$ e $0,8 \mathrm{~g}$ de ácido lático para cada litro de leite e soro, respectivamente. Em seguida, adicionaram-se os outros ingredientes, açúcar e amido previamente diluído em parte do leite utilizado na fabricação. Iniciou-se, então, o processo de concentração do doce de leite com agitação até atingir um teor de sólidos solúveis de aproximadamente $67{ }^{\circ}$ Brix. O total de sólidos solúveis foi determinado usando um refratômetro portátil modelo RT-82 e o ${ }^{\circ} \mathrm{Brix}$ foi medido na temperatura de $25{ }^{\circ} \mathrm{C}$. Após medição do ponto, os doces foram envasados em potes de 200 gramas e armazenados para a realização das análises.

\section{Rendimento}

O rendimento do processamento das diferentes formulações foi avaliado conforme fórmula descrita por Martins; Lopes (1981):

$$
\mathrm{R}=\frac{(\mathrm{SM} \times 100)}{\mathrm{SD}} \text {, onde: }
$$

$\mathrm{R}$ - rendimento, em $\mathrm{kg}$ de doce de leite;

$\mathrm{SM}$ - matéria seca da mistura;

$\mathrm{SD}$ - matéria seca do doce de leite.

\section{Viabilidade econômica}

Para a realização da avaliação econômica, primeiramente foram calculados os investimentos físicos e financeiros. Com esses dados foi feito o levantamento dos custos, que são fixos ou variáveis.

De posse do custo total (custos fixos e custos variáveis) fez-se o cálculo do preço de venda estimado do produto (PUV), conforme Equação 1. Para obter o preço de venda do produto foi necessário o cálculo do custo variável por unidade produzida (CVU) (Equação 2), custo fixo unitário (CFU) (Equação 3) e custo unitário do produto (CUP) (Equação 4) (ROCHA, 2011).

$$
\mathrm{PUV}=\frac{\mathrm{CUP}}{[100 \%-(\mathrm{CC} \%+\mathrm{ML} \%)]} \times 100
$$

Equação 1 - Preço de venda estimado - PUV Para o cálculo do preço de venda do 
produto foi considerado o custo de comercialização $(\mathrm{CC} \%)$ igual a $15 \%$, custo de divulgação $(3,4 \%)$, impostos $(8,6 \%)$, previsões de perda $(1,5 \%)$, comissões de venda $(1,5 \%)$ e a margem de lucro (ML\%) bruta de $30 \%$.

$$
\text { CVU }=\frac{\text { Custo Variável Total }}{\text { Quantidade produzida }}
$$

Equação 2 - Custo variável por unidade produzida - CVU

$$
\mathrm{CFU}=\frac{\text { Custo Fixo Total }}{\text { Quantidade produzida }}
$$

Equação 3 - Custo fixo unitário - CFU

$$
\mathrm{CUP}=\mathrm{CVU}+\mathrm{CFU}
$$

Equação 4 - Custo unitário do produto - CUP

Determinado o preço de venda e custos fez-se uma estimativa do lucro e uma avaliação econômica usando parâmetros financeiros como rentabilidade, lucratividade, prazo de retorno do investimento e ponto de equilíbrio.

A lucratividade, rentabilidade e prazo de retorno do investimento (PRI) foram calculados conforme Equação 5, Equação 6 e Equação 7, respectivamente (ROCHA, 2011).

Lucratividade $=\frac{\text { Lucro Líquido }}{\text { Receita Total }} \times 100$

Equação 5 - Lucratividade
Rentabilidade $=\frac{\text { Lucro Líquido }}{\text { Investimento Total }}$

Equação 6 - Rentabilidade

$$
\text { PRI }=\frac{\text { Investimento Total }}{\text { Lucro Líquido }}
$$

Equação 7 - Prazo de retorno do investimento

Para o cálculo do ponto de equilíbrio (Equação 8) foi preciso primeiramente calcular a margem de contribuição unitária (MCU) (Equação 9) (ROCHA, 2011).

$$
\mathrm{PE}=\frac{\text { Custos Fixos }}{\mathrm{MCU}}
$$

Equação 8 - Ponto de equilíbrio

$$
\mathrm{MCU}=\mathrm{PUV}-\mathrm{CVU}
$$

Equação 9 - Margem de contribuição unitária

\section{Análise estatística}

Os resultados experimentais de rendimento foram realizados com três repetições e submetidos à análise de variância (ANOVA), seguida de teste de médias (Tukey, $\mathrm{p}<0,05$ ), utilizando o software Statistica ${ }^{\circledR} 5.0$ (StatSoft, Poland). Para os cálculos econômicos foram utilizadas as equações apresentadas na metodologia.

Tabela 2 - Rendimento obtido das formulações testadas ${ }^{1}$

\begin{tabular}{lcccc}
\hline \multicolumn{5}{c}{ Rendimento $(\%)^{2}$} \\
\hline F1 & F2 & F3 & F4 & F5 \\
\hline $40,16 \mathrm{a} \pm 0,12$ & $39,26 \mathrm{~b} \pm 0,19$ & $38,36 \mathrm{c} \pm 0,10$ & $36,17 \mathrm{~d} \pm 0,20$ & $33,89 \mathrm{e} \pm 0,40$ \\
\hline $\begin{array}{l}{ }^{1} \text { Médias (três repetições) nas linhas seguidas por letras iguais não diferem entre si, a 5\% de significância, pelo } \\
\text { teste de Tukey. } \\
{ }^{2} \%=\text { Kg de doce em } 100 \mathrm{Kg} \text { de mistura (leite + soro + açúcar + amido). }\end{array}$
\end{tabular}




\section{RESULTADOS E DISCUSSÃO}

Na Tabela 2 são apresentados os resultados de rendimento das 5 formulações obtidas (F1, F2, F3, F4 e F5).

Houve diferença significativa no rendimento das formulações. Quanto maior a substituição de leite por soro, menor o rendimento (Tabela 2). Segundo Perrone et al. (2011) ao substituir parte do leite por soro na produção de doce há uma diminuição do rendimento de fabricação, causado por um menor teor de sólidos láticos inicial da mistura leite e soro.

Os resultados obtidos corroboram com Machado (2005) que encontrou maiores rendimentos quando os doces foram elaborados sem adição de soro de queijo, independente da concentração de amido utilizada.

$\mathrm{Na}$ Tabela 3 estão representados os investimentos iniciais e financeiros, para a pro- dução do doce de leite com adição de soro lácteo.

Para o início da produção do doce de leite com soro é necessário um investimento físico de R $\$ 190,00$ (US\$ 58,55) referente à compra de uma panela e uma colher e um investimento financeiro de $\mathrm{R} \$ 169,26$ reais (US\$ 52,16), totalizando um investimento total de $\mathrm{R} \$ 359,26$ reais (US\$110,72). $\mathrm{O}$ investimento financeiro corresponde à matériaprima referente à produção de um mês, equivalente a 20 litros de mistura (leite + soro).

A Tabela 4 demonstra os custos fixos para a produção do doce de leite com soro lácteo por dia.

O custo fixo para a produção do doce de leite com soro lácteo ficou em $\mathrm{R} \$ 18,00$ (US\$ $5,55)$ (energia elétrica, impostos, etc.).

Os custos variáveis para a produção do doce de leite com adição de soro lácteo estão representados na Tabela 5.

Tabela 3 - Investimento físico e financeiro para fabricação do doce de leite com adição de soro lácteo

\begin{tabular}{l|c}
\hline \multicolumn{1}{c|}{ Investimento físico } & Investimento financeiro R\$ (US\$)* \\
\hline Panela & $180,00(55,47)$ \\
Colher & $10,00(3,08)$ \\
Estoque de matéria-prima (açúcar e amido)** & $169,26(52.16)$ \\
\hline Investimento Total & $359,26(110,72)$ \\
\hline
\end{tabular}

* US\$: valor em dólar (valor atual: $\mathrm{R} \$ 3,20$ )

** Matéria-prima referente à produção de um mês, equivalente a uma panela de 20 litros de mistura (leite + soro)

Fonte: Banco Central do Brasil.

Tabela 4 - Custos fixos para a produção do doce de leite com adição de soro lácteo

\begin{tabular}{c|c}
\hline & Custos fixos R\$(US\$)* \\
\hline Energia elétrica & $8,00(2,47)$ \\
Outros (impostos, etc.) & $10,00(3,08)$ \\
\hline Total & $18,00(5,55)$ \\
\hline
\end{tabular}

* US\$: valor em dólar (valor atual: R\$3,20)

Fonte: Banco Central do Brasil 
Os custos variáveis foram calculados considerando uma produção de $20 \mathrm{~L}$ de mistura (leite + soro). Para essa quantidade, são obtidas 39 unidades de doce para a formulação $1 ; 38$ unidades para a formulação $2 ; 37$ unidades para a formulação $3 ; 35$ unidades para a formulação 4 e 33 unidades para a formulação 5 .

Após a obtenção dos custos fixos e variáveis, calculou-se o custo unitário do produto (Tabela 6).

O preço de venda das formulações do doce de leite com adição de soro lácteo está descrito na Tabela 7.

Com a posse de todos os dados necessários, estimou-se o valor de venda (receita), custo total e o lucro (Tabela 8).

Após o cálculo dos custos e dos investimentos necessários, realizaram-se os cálculos dos indicadores de desempenho.

Na Tabela 10 está representada a lucratividade obtida com a produção do doce de leite com adição de soro lácteo.

Tabela 5 - Custos variáveis para a produção do doce de leite com adição de soro lácteo

\begin{tabular}{c|c|c|c|c|c}
\hline \multirow{2}{*}{$\begin{array}{c}\text { Custos } \\
\text { variáveis }\end{array}$} & $\mathrm{F} 1$ & $\mathrm{~F} 2$ & $\mathrm{~F} 3$ & $\mathrm{~F} 4$ & $\mathrm{~F} 5$ \\
\cline { 2 - 6 } & $\mathrm{R}(\mathrm{US} \$)^{*}$ & $\mathrm{R} \$(\mathrm{US} \$)^{*}$ & $\mathrm{R} \$(\mathrm{US} \$)^{*}$ & $\mathrm{R} \$(\mathrm{US} \$)^{*}$ & $\mathrm{R} \$(\mathrm{US} \$)^{*}$ \\
\hline Leite & $15,30(4,72)$ & $13,60(4,19)$ & $11,90(3,67)$ & $10,20(3,15)$ & $8,50(2,62)$ \\
Soro & $0,00(0,00)$ & $0,00(0,00)$ & $0,00(0,00)$ & $0,00(0,00)$ & $0,00(0,00)$ \\
$\begin{array}{c}\text { Açúcar } \\
\text { Bicarbonato } \\
\text { de sódio }\end{array}$ & $4,68(1,44)$ & $4,68(1,44)$ & $4,68(1,44)$ & $4,68(1,44)$ & $4,68(1,44)$ \\
$\begin{array}{c}\text { Amido } \\
\text { Embalagem }\end{array}$ & $0,12(0,04)$ & $0,12(0,04)$ & $0,12(0,04)$ & $0,12(0,04)$ & $0,12(0,04)$ \\
(pote de vidro) & $57,84(17,82)$ & $56,54(17,42)$ & $55,23(17,02)$ & $52,09(16,05)$ & $48,80(15,04)$ \\
Outros & $18,00(5,55)$ & $18,00(5,55)$ & $18,00(5,55)$ & $18,00(5,55)$ & $18,00(5,55)$ \\
\hline Total & $96,91(29,87)$ & $93,91(28,94)$ & $90,90(28,01)$ & $86,06(26,52)$ & $81,07(24,98)$ \\
\hline
\end{tabular}

* valor em dólar (valor atual: US\$ 3,20)

Fonte: Banco Central do Brasil

Tabela 6 - Custos unitários das formulações do doce de leite com adição de soro lácteo

\begin{tabular}{c|c|c|c|c|c}
\hline \multirow{2}{*}{ Custos } & F1 & F2 & F3 & F4 & F5 \\
\cline { 2 - 6 } & $\mathrm{R} \$(\mathrm{US} \$)^{*}$ & $\mathrm{R} \$(\mathrm{US} \$)^{*}$ & $\mathrm{R} \$(\mathrm{US} \$)^{*}$ & $\mathrm{R} \$(\mathrm{US} \$)^{*}$ & $\mathrm{R} \$(\mathrm{US} \$)^{*}$ \\
\hline $\begin{array}{c}\text { Custo fixo } \\
\text { unitário }\end{array}$ & $0,46(0,14)$ & $0,47(0,14)$ & $0,48(0,15)$ & $0,51(0,16)$ & $0,55(0,17)$ \\
\hline $\begin{array}{c}\text { Custo variável } \\
\text { unitário }\end{array}$ & $2,49(0,77)$ & $2,47(0,76)$ & $2,46(0,76)$ & $2,46(0,76)$ & $2,46(0,76)$ \\
\hline Total & $2,95(0,91)$ & $2,94(0,91)$ & $2,94(0,91)$ & $2,97(0,92)$ & $3,01(0,93)$ \\
\hline
\end{tabular}

* valor em dólar (valor atual: US\$ 3,20)

Fonte: Banco Central do Brasil 
Tabela 7 - Preço estimado de venda por unidade do doce de leite com adição de soro lácteo

\begin{tabular}{c|c|c|c|c|c}
\hline \multirow{2}{*}{} & \multicolumn{5}{|c}{ Preço de venda R\$ (US\$)* } \\
\cline { 2 - 6 } & F1 & F2 & F3 & F4 & F5 \\
\hline Unidade & $5,36(1,65)$ & $5,35(1,65)$ & $5,35(1,65)$ & $5,40(1,66)$ & $5,47(1,69)$ \\
\hline
\end{tabular}

* valor em dólar (valor atual: US\$ 3,20)

Fonte: Banco Central do Brasil

Tabela 8 - Valores de produção de doce de leite com adição de soro lácteo

\begin{tabular}{|c|c|c|c|c|c|}
\hline & \multicolumn{5}{|c|}{ Valores de produção } \\
\hline & $\mathrm{F} 1$ & $\mathrm{~F} 2$ & F3 & F4 & F5 \\
\hline & $\mathrm{R} \$(\mathrm{US} \$)^{*}$ & $\mathrm{R} \$(\mathrm{US} \$)^{*}$ & $\mathrm{R} \$(\mathrm{US} \$)^{*}$ & $\mathrm{R} \$(\mathrm{US} \$)^{*}$ & $\mathrm{R} \$(\mathrm{US} \$)^{*}$ \\
\hline \multirow{2}{*}{$\begin{array}{l}\text { Quantidade } \\
\text { produzida }\end{array}$} & 39 & 38 & 37 & 35 & 33 \\
\hline & $\mathrm{R} \$(\mathrm{US} \$)^{*}$ & $\mathrm{R} \$(\mathrm{US} \$)^{*}$ & $\mathrm{R} \$(\mathrm{US} \$)^{*}$ & $\mathrm{R} \$(\mathrm{US} \$)^{*}$ & $\mathrm{R} \$(\mathrm{US} \$)^{*}$ \\
\hline Custo total & $96,91 \quad(29,87)$ & 93,91 $(28,94)$ & $90,90(28,01)$ & $86,06(26,52)$ & $81,07 \quad(24,98)$ \\
\hline Receita & $209,18 \quad(64,46)$ & $203,13(62,60)$ & $197,78(60,95)$ & $189,00(58,25)$ & $180,60(55,66)$ \\
\hline Lucro total & $112,27(34,6)$ & $109,22 \quad(33,66)$ & $106,88 \quad(32,94)$ & $102,94(31,72)$ & $99,53(30,67)$ \\
\hline Lucro líquido & $95,43(29,41)$ & $92,84(28,61)$ & $90,85(28,00)$ & $87,50(26,97)$ & $84,60(26,07)$ \\
\hline
\end{tabular}

* US\$: valor em dólar (valor atual: $\mathrm{R} \$ 3,20$ )

Fonte: Banco Central do Brasil.

Tabela 9 - Lucratividade obtida com a produção do doce de leite com adição de soro lácteo

\begin{tabular}{ccccc}
\hline \multicolumn{5}{c}{ Lucratividade } \\
\hline F1 & F2 & F3 & F4 & F5 \\
$45,62 \%$ & $45,70 \%$ & $45,93 \%$ & $46,30 \%$ & $46,84 \%$ \\
\hline
\end{tabular}

Tabela 10 - Rentabilidade para a produção do doce de leite com adição de soro lácteo

\begin{tabular}{c|c|c|c|c}
\hline \multicolumn{5}{c}{ Rentabilidade R\$ (US\$)* } \\
\hline F1 & F2 & F3 & F4 & F5 \\
\hline $26,56(8,29)$ & $25,84(8,07)$ & $25,29(7,90)$ & $24,36(7,61)$ & $23,55(7,35)$ \\
\hline
\end{tabular}

* valor em dólar (valor atual: US\$ 3,20)

Fonte: Banco Central do Brasil. 
A lucratividade representa a eficiência operacional, ou seja, a cada $\mathrm{R} \$ 100,00$ reais (US\$ 31,23) vendidos, restam para o produtor $\mathrm{R} \$ 45,62$ reais (US\$ 14,25); R\$ 45,70 reais (US\$ 14,27); R\$ 45,93 reais (US\$ 14,34); $\mathrm{R} \$ 46,30$ reais (US\$ 14,46); R\$ 46,84 reais (US\$ 14,63), para as formulações F1; F2; F3; F4 e F5, respectivamente, como forma de lucro, depois de pago todos os impostos, ou seja, quanto maior a porcentagem de soro maior a lucratividade.

A rentabilidade foi de aproximadamente $27 \%$ para a formulação 1 (Tabela 10 ), ou seja, $27 \%$ de tudo que foi investido retornam em um mês sob a forma de lucro. A rentabilidade diminui conforme aumenta a porcentagem de soro.

Na Tabela 11 está representado o prazo de retorno de investimento referente às 5 formulações testadas.

Tabela 11 - Prazo de retorno do investimento para a produção do doce de leite com adição de soro lácteo

\begin{tabular}{c|c|c|c|c}
\hline \multicolumn{5}{c}{ Prazo de retorno do investimento (meses) } \\
\hline F1 & F2 & F3 & F4 & F5 \\
\hline 3,76 & 3,87 & 3,95 & 4,11 & 4,25 \\
\hline
\end{tabular}

O prazo de retorno do investimento resultou em aproximadamente 4 meses para todas as formulações (Tabela 11), o que significa que caso seja alcançado a expectativa de venda, o produtor recupera tudo que investiu em 4 meses.

Na Tabela 12 o ponto de equilíbrio para a produção do doce de leite com adição de soro lácteo para as 5 formulações testadas. Segundo Rezende et. al (2006), o ponto de equilíbrio refere-se ao nível de produção em que não há lucro ou prejuízo. Assim, nesse parâmetro é demonstrado o quanto deverá ser vendido mensalmente de cada produto para cobrir seus custos.
Tabela 12 - Ponto de equilíbrio para a produção do doce de leite com adição de soro lácteo

\begin{tabular}{c|c|c|c|c}
\hline \multicolumn{5}{c}{ Ponto de equilíbrio } \\
\hline F1 & F2 & F3 & F4 & F5 \\
\hline R \$ 8,36 & $\mathrm{R} \$ 8,32$ & $\mathrm{R} \$ 8,28$ & $\mathrm{R} \$ 8,20$ & $\mathrm{R} \$ 8,09$ \\
\hline
\end{tabular}

Observou-se que o ponto de equilíbrio para o doce se encontra na venda de 8 unidades, ou seja, vendendo 8 unidades do doce por mês, o produtor não apresenta lucro ou prejuízo, cobrindo todos os seus custos.

Portanto, observa-se que esse produto é viável economicamente, caso seja possível a demanda de todo o doce produzido, no entanto, a partir de 8 unidades o produtor já obterá lucro.

Estudos realizados comprovam a viabilidade de produção de doce de leite com a adição de soro. Machado (2005) estudou a aceitação de doce de leite com adição de diferentes concentrações de soro de leite e amido de milho modificado e relatou que quanto maior a porcentagem de soro, independente da porcentagem de amido e do tempo de armazenamento, melhor foi a aparência, a intenção de compra, a cor, a consistência e a avaliação de modo geral dos doces de leite.

Ferreira et al. (2009) avaliaram a aceitação de doce de leite sabor café, com e sem adição de soro. Segundo Ferreira et al. (2009) os doces apresentaram boa aceitação e a adição de soro não interferiu na aceitação dos doces.

Ferreira-Rocha (2013) avaliou o efeito do tempo de armazenamento nas características do doce de leite sabor café com adição de soro de leite e amido modificado, e demonstrou que não houve formação de cristais de lactose, a qualidade microbiológica foi mantida durante todo o período de estocagem do doce e o tempo não influenciou na aceitação do doce em relação ao sabor, 
textura e impressão global, constituindo uma alternativa de utilização do soro de leite.

\section{CONCLUSÕES}

A formulação com $10 \%$ de soro teve maior rendimento devido a menor utilização de soro lácteo. Em relação a lucratividade, a formulação com maior porcentagem de soro se mostrou mais lucrativa (46,84\%).

A rentabilidade foi de aproximadamente $27 \%$ para a formulação com menor porcentagem de soro lácteo e a mesma diminui conforme aumenta a porcentagem do soro. O ponto de equilíbrio para o doce de leite com soro lácteo se encontra na venda de 8 unidades para todas as formulações, ou seja, vendendo a partir de 8 unidades do doce por mês, o produtor consegue cobrir seus custos e obter lucro. Portanto, observa-se que a produção de doce de leite com soro é viável técnica e economicamente.

\section{REFERÊNCIAS}

ABREU, L. R. de. Tecnologia de leite e derivados. Lavras: UFLA/FAEPE, 1999, $205 \mathrm{p}$.

BALDASSO, C.; BARROS, T. C.; TESSARO, I. C. Concentration and purification of whey proteins by ultrafiltration. Desalination, v. 278, p. 381-386, 2011.

CARVALHO, F.; PRAZERES, A. R.; RIVAS, J. Cheese whey wastewater: Characterization and treatment. Science of the Total Environment, v. 445-446, p. 385-396, 2013.

\section{COPSERRO. Cooperativa dos Produto-} res Rurais do Serro. Informação pessoal: copserro@uai.com.br. Agosto de 2013.

EMATER. Empresa de Assistência Técnica e Extensão Rural. Mapa do queijo.
Disponível em: <http://www.emater.mg.gov. br/portal.cgi?flagweb=site_pgn_downloads vert\&grupo $=135 \&$ menu $=59>$. Acesso em: 22 out. 2015.

FERREIRA, L. O. et al. Avaliação sensorial de doce de café com leite e soro: teste afetivo e mapa de preferência. In: CONGRESSO DE PÓS-GRADUAÇÃO DA UFLA, 18, 2009, Lavras. Anais... Lavras, 2009.

FERREIRA-ROCHA, L. O. Utilização de soro lácteo, goma xantana e amido modificado na elaboração de doce de leite com café. 2013. 204p. Tese (Doutorado em Ciência dos Alimentos) - Universidade Federal de Lavras, Lavras, 2013.

GIROTO, G. M.; PAWLOWSKY, U. O soro de leite e as alternativas para o seu beneficiamento. Brasil Alimentos, n. 10, set./ out., 2001.

IMA. Instituto Mineiro de Agropecuária. 2015. Queijo Minas Artesanal. Disponível em: <http:/www.ima.mg.gov.br/certificacao/ queijo-minas-artesanal-link>. Acesso em: 14 out. 2015.

MACHADO, L. M. P. Uso de soro de queijo e amido de milho modificado na qualidade do doce de leite pastoso. 2005. 170p. Tese (Doutorado em Tecnologia de Alimentos) - Universidade Estadual de Campinas, Faculdade de Engenharia de Alimentos, Campinas, 2005.

MARTINS, J. F. P.; LOPES, C. N. Doce de leite: aspectos da tecnologia de fabricação. Campinas: Instituto de Tecnologia de Alimentos, 1981. p. 1-37. (Instruções técnicas, n. 18).

MARTINS, J. M. Características físico- 
químicas e microbiológicas durante a maturação do queijo Minas Artesanal da região do Serro. 2006. 146 p. Tese (Doutorado em Ciência e Tecnologia de Alimentos) - Universidade Federal de Viçosa, Viçosa, 2006.

OGAL. Observatório Geográfico da América Latina. Disponível em: $<$ http:// observatoriogeograficoamericalatina.org.mx/ egal12/Geografiasocioeconomica/Geografia cultural/114.pdf>. Acesso em: 05 set. 2013.

PERRONE, I. T. Efeito da nucleação secundária sobre a cristalização do doce de leite. 2006. 49 p. Dissertação (Mestrado em Ciência dos Alimentos) - Universidade Federal de Lavras, Lavras, 2006.

PERRONE, L. T.; STEPHANI, R.; NEVES, B. S. Doce de Leite: aspectos tecnológicos. Juiz de Fora, 2011. 185 p.

PINDYCK, R. S.; RUBINFELD, D. L. Microeconomia. $5^{\mathrm{a}}$ ed. São Paulo: Prentice Hall, 2002. 712 p.

REZENDE, A. A.; SANTOS, A. C.; COSTA, A. M. Custo de produção em laticínios. Cus- tos e Agronegócios On line, Recife, v. 2, n. 1, jan/jun, 2006.

ROCHA, L. O. F. Utilização de soro lácteo, goma xantana e amido modificado na elaboração de doce de leite com café. 2013. 204 p. Tese (Doutorado em Ciência dos Alimentos) - Universidade Federal de Lavras, Lavras, 2013.

ROCHA, M. R. Viabilidade técnica e econômica do novo produto: goiabada cascão diet com adição de prebióticos. 2011. 51 p. Monografia (Bacharel em Engenharia de Alimentos) - Universidade Federal de Lavras, Lavras, 2011.

SANTOS, A. S. Queijo Minas artesanal da microrregião do Serro-MG: efeito da sazonalidade sobre a microbiota do leite cru e comportamento microbiológico durante a maturação. 2010. Dissertação (Programa de Pós Graduação em Zootecnia). Universidade Federal dos Vales do Jequitinhonha e Mucuri, Diamantina, 2010.

SGARBIERI, V. C. Proteínas em alimentos protéicos: propriedades, degradações, modificações. São Paulo: Varela, 1996, 517p. 